\title{
Миграционная повестка в итальянских СМИ
}

(деонтологический и практический аспекты)

Анастасия Груша

Камажан Урманбаева

В статье приведен контент-анализ публикаций о четырех значимых миграционных событиях в двух ведущих итальянских газетах La Repubblica и Corriere della Sera, направленный на выявление и сравнение образа мигрантов и миграции, выделены основные тенденции в освещении миграционной темы, изучен деонтологический контекст освещения миграционных проблем и итальянские механизмы этического регулирования в данной сфере.

Ключевые слова: Италия, Il Corriere, La Repubblica, миграция, мигранты

DOI: 10.30547/mediaalmanah.5.2020.113122
@ Груша Анастасия Вячеславовна кандидат филологических наук, доцент кафедры периодической печати факультета журналистики МГУ имени М.В. Ломоносова

(г. Москва, Россия), anastasia_grusha@mail.ru

@ Урманбаева Камажан Еркозыевна выпускница бакалавриата факультета журналистики МГУ имени М.В. Ломоносова (г. Москва, Россия), urmanbaeva@gmail.com

\section{Тема миграции: деонтологический контекст и механизмы этического регулирования}

Миграция является одной из острейших тем в современной Италии, и общественная реакция на нее разнится от сострадания и желания помочь людям в беде до раздражения на преступников и нахлебников, ищущих лучшей жизни (Гоффе, 2017; Казаринова, де Лука, 2020). Мигранты зачастую "обвиняются в проблемах народа» и тем самым используются политическими движениями, в той или иной степени играющими на расистских настроениях среди населения (Зонова, 2015). Риторика переживающих подъем в Европе правопопулистских движений «имеет особенно сильное влияние на антииммигрантские настроения» (Wirz et al., 2018: 500).

Проблема расизма в отношении мигрантов особенно актуальна для Италии, в которой большинство иммигрантов - искателей убежища имеют африканское происхождение и потому легко могут стать мишенью расистских высказываний и действий.

Чувствительностью данной темы для населения и риском провоцирования дискриминации обусловлена необходимость особого внимания к соблюдению этических норм при освещении миграционных проблем в СМИ и, следовательно, определенного контроля над работой журналистов. 
В итальянском законодательстве профессиональная деятельность журналистов регулируется Законом № 69 от 3 февраля 1963 г. «Порядок профессии журналиста» (Ordinamento della Professione di Giornalista). Уже в тексте закона указывается на необходимость «защиты чужой личности», что применимо к нашей теме: «Нерушимым правом журналистов является свобода информации и критики, ограниченная соблюдением законодательных норм, направленных на защиту чужой личности, и их не приемлющей отступлений обязанностью является соблюдение истинности фактов при постоянном соблюдении обязанностей, накладываемых честностью и добросовестностью. Должны быть скорректированы новости, которые оказываются неточными, и исправлены возможные ошибки» (ст. 2. «Права и обязанности»)1.

Тот же закон предусматривает саморегуляцию журналистского сообщества и учреждает Союз журналистов (Ordine dei Giornalisti), на который возлагается эта функция: «Обращается внимание <...> на всю деликатность вмешательства государства или других внешних субъектов, которые устанавливали бы ограничения независимости информации. <...> определенные вмешательства, например деонтологической природы, возлагаются на органы профессии, будь то профессиональные объединения, профсоюзы или ассоциации...»².

Этические нормы журналистской профессии закреплены в Хартии обязанностей журналиста 1993 г. В этом тексте содержатся положения о недопустимости различных видов дискриминации, в частности по признаку расы и религии, но в качестве уязвимых групп указываются только люди с инвалидностью и несовершеннолетние ${ }^{3}$, специальное внимание вопросу мигрантов не уделяется.

Существует и этический инструмент, полностью посвященный работе журналистов при освещении миграции. В 2008 г. Национальным советом Союза журналистов и Национальной федерацией итальянской печати при содействии Управления Верховного комиссара ОOH по делам беженцев (UNHCR) была разработана Римская хартия (Carta di Roma) - «деонтологический протокол, касающийся искателей убежища, беженцев, жертв эксплуатации и мигрантов». Римская хартия занимает четкую позицию защиты мигрантов и не претендует на полный нейтралитет, о чем говорится в последнем издании практических рекомендаций по применению Хартии: «Наша хартия <...> не нейтральна, поскольку основывается на ценностях антифашизма, антирасизма, социальной инклюзии, солидарности и гостеприимства»4. Данный документ предписывает журналистам, вопервых, выбирать «юридически подходящие термины с целью предоставить читателю и пользователю факты в максимальном соответствии с реальностью, избегая использования неподобающихтерминов»; во-вторых, «избегать распространения неточных, обобщенных или искаженных сведений в отношении искателей убежища, беженцев, жертв эксплуатации и мигрантов»; в-третьих, «защищать [тех из них], кто соглашается говорить с журналистами», не допуская их идентификации; и, в-четвертых, «обращаться к экспертам и специализированным организациям, чтобы представлять публике информацию в ясном и полном контексте, учитывая и причины явлений» ${ }^{5}$. К хартии прилагается глоссарий, содержащий юридически верные определения терминов, наиболее употребляемых (часто без должного внимания к их точному значению) при обсуждении миграции («искатель убежища», «беженец», «гуманитарная и дополнительная защита», «жертва эксплуатации» и пр.) ${ }^{6}$.

Римская хартия также предусматривает включение миграционной проблематики в программу образовательных курсов и мероприятий Союза журналистов и Национальной федерации итальянской печати, создание специальных 
наград и учреждение независимой организации для мониторинга публикуемой в СМИ информации об искателях убежища, беженцах, жертвах эксплуатации и мигрантах, анализа их образа в СМИ и «предоставления материала для размышления и сравнения» региональным союзам журналистов и другим ответственным организациям".

Римская хартия была включена в Сводный текст обязанностей журналиста (Testo unico dei doveri del giornalista) 2016 г.: обязанности в отношении иностранных граждан выделены в ней в отдельную статью внутри раздела, посвященного обязанностям журналистов в отношении людей, с которыми они контактируют и о которых рассказывают. В данной статье в кратком виде утверждается необходимость выбора юридически правильных терминов и защиты идентичности людей, которые соглашаются выступить в медиав.

Отдельно прописывая нормы работы журналистов с иностранными гражданами в общем этическом кодексе, итальянский Союз журналистов осознает наличие и важность освещения проблемы лиц иностранного происхождения в СМИ, признает, что они представляют собой уязвимую категорию населения, что требует от журналистов особой осторожности в обращении с ними, и занимает позицию защиты иностранных граждан.

В 2011 г. была создана Ассоциация «Карта ди Рома» (Associazione Carta di Roma), нацеленная на осуществление принципов Деонтологического протокола и позиционирующая себя как шустойчивый ориентир для всех, кто постоянно работает над темами Хартии», включая в первую очередь журналистов, но также отдельных активистов и организации ${ }^{9}$. Ее деятельность включает организацию различных образовательных проектов, мониторинг информации в СМИ, продвижение инициатив по ответственной и продуманной работе с информацией по миграционной теме, развитие сотрудничества между различными общественными акторами, способными влиять на ситуацию с соблюдением прав мигрантов в итальянском обществе.

Ассоциация ежегодно подготавливает и выпускает доклады, посвященные анализу темы миграции в итальянских СМИ, в которых подсчитывается количество материалов, посвященных миграции, в разных СМИ и выявляется их общий тон и ключевые тенденции в освещении этой темы.

В дополнение к деонтологическому протоколу Ассоциация «Карта ди Рома» также периодически публикует практические рекомендации (Linee guida) для журналистов по применению Хартии, в которых более подробно раскрывается и обосновывается каждый ее принцип, приводятся конкретные указания для работы в определенных ситуациях и примеры.

Практические рекомендации содержат расширенный глоссарий, охватывающий не только различия в юридическом статусе мигрантов, но и лексику, касающуюся морских спасательных операций, отдельных религиозных и этнических меньшинств, правительственных действий в отношении иностранцев на территории государства. В этом же документе содержится объемный список достоверных и компетентных источников юридической, статистической, экономической, научной информации о миграции в различных ее аспектах.

Комментируя второй принцип Хартии защиту идентичности героев журналистских материалов, - авторы документа призывают быть внимательными к стране происхождения мигрантов, во-первых, в связи с тем, что люди, мировоззрение которых сформировалось под влиянием иных социокультурных традиций, где «роль СМИ ограничена», могут быть «не в состоянии оценить все последствия своего появления в медиа»10, и, во-вторых, в силу того, что публикация каких-либо элементов, позволяющих идентифицировать человека, могут подвергнуть его и/или его близких, 
оставшихся на родине, риску преследования со стороны его государства"1.

В соответствии с третьим принципом корректностью и полнотой информации Ассоциация рекомендует «контекстуализировать новости, рассказывать о <...> причинах отъезда, хронике путешествий таким образом, чтобы <...> читатели и слушатели могли прочесть о тех организациях и людях, с которыми [журналист] входит в контакт»12. Этот же принцип распространяется на обсуждение в СМИ преступности, медицинских опасений, расизма, проблем трудоустройства и культурной идентичности. Авторы документа заостряют внимание на языке вражды (hate speech), особенно в случаях, когда высказывания подобного рода исходят от известных политических деятелей, которые тем самым ставят журналистов перед выбором, как правильно их преподнести и нужно ли делать их достоянием общественности.

Ассоциация «Карта ди Рома» при определенных условиях предлагает вообще отказаться от публикации таких высказываний: «Политик-подстрекатель, умеющий манипулировать публикой, не должен получать освещения в медиа, поскольку оно может создать негативный климат <...> Медиа должны гарантировать, что они не привлекают чрезмерное внимание к политикам и другим влиятельным людям, чья единственная цель состоит в создании негативного климата по отношению к определенным группам людей, особенно когда они представляют собой наиболее уязвимые категории»13. Таким образом, в случае с выступлениями публичных лиц Ассоциация призывает медиа принять на себя роль «фильтра» высказываний, попадающих в СМИ, а не простого «передатчика» выступлений публичных деятелей, даже если те обладают высоким статусом и уровнем влияния. Такой подход отвечает функции «морального контроля [СМИ] над политикой» (Marini, Gerli, 2017: 501), но в то же время у некоторых исследователей возникают и опасения в связи с тем, что сильная фильтрация информации в традиционных, наиболее авторитетных СМИ, придерживающихся этических норм, их стремление сохранить сбалансированность информации может вытолкнуть напряженность и ярко негативные оценки в миграционных вопросах в другие издания, а именно в онлайн, где в силу этого усиливается аллармизм (Урина, 2017: 102).

\section{Освещение миграционной повестки в газетах La Repubblica и Corriere della Sera}

В рамках исследования проанализировано освещение нескольких событий, особенно важных в контексте миграционной проблемы и вызвавших сильный отклик в итальянском обществе.

Многочисленные исследования обнаруживают сильную тенденцию к «крими нализации» образа иммиграции в медиа, к настойчивой ассоциации между иммиграцией и преступностью. Чрезвычайную огласку в национальных СМИ (особенно в контексте парламентских выборов 2018 г.) получили трагические события в городе Мачерата: 31 января 2018 г. несколько иммигрантов жестоко убили 18-летнюю Памелу Мастропьетро, а 3 февраля итальянец Лука Траини открыл стрельбу по случайным темнокожим людям. Как заявлял стрелявший, его нападение было ответом на убийство девушки ${ }^{14}$. Освещение этих двух происшествий в выбранных изданиях привлекло наше внимание, поскольку это два связанных друг с другом криминальных эпизода исключительной жестокости, в одном из которых иммигранты были нападавшими, а в другом пострадавшими, что позволяет отследить соотношение образов иммигрантов как преступников и как жертв.

Проблема незаконной миграции широко обсуждалась в преддверие парламентских выборов 2018 г. и явно использовалась некоторыми партиями в предвыборных кампаниях. Регулирование миграционного потока в страну было в числе ключевых 
вопросов, обсуждавшихся партиями и СМИ. Наибольшее количество голосов в результате выборов получил правоцентристский блок. Лидирующая внутри него партия «Лига»15 (и особенно ее глава Маттео Сальвини, назначенный министром внутренних дел и одним из вице-премьеров) в предвыборной кампании во многом делала упор на призывы к жесткому ограничению иммиграции. При этом количество принимаемых Италией мигрантов снизилось на 80\% за последний год ${ }^{16}$, однако объем освещения миграционной проблемы в СМИ мало изменился, а общий тон публикаций эксперты Ассоциации «Карта ди Рома» охарактеризовали как «внушающий тревогу тон постоянной чрезвычайной ситуации»17.

И если миграционная повестка партий в какой-либо степени повлияла на предпочтения избирателей, то важную роль в формировании их мнения о масштабе и надлежащих способах решения этой проблемы должно было сыграть то, как она была представлена в предвыборный период в СМИ.

Еще один распространенный мотив рассказа о мигрантах в медиа - это подтема гуманитарного кризиса, сострадания. В рамках этой подтемы мигранты зачастую представляются в виде жертв бедственной обстановки в своей стране, вынужденных бежать в Европу и жить в нищете. Этот мотив часто задействуется при описании трагедий в Средиземном море (Marini, Gerli, 2017). Одна из ситуаций подобного рода произошла в июне 2018 г. с гуманитарным судном "Аквариус» (Aquarius), перевозившим несколько сотен беженцев, подобранных в Средиземном море: Италия демонстративно отказалась принять судно на своей территории. «Аквариус» был вынужден оставаться в открытом море в течение нескольких дней до того, как его согласилась принять Испания и судно направилось в Валенсию. Этот жест нового итальянского правительства одни восприняли как жестокую, но необходимую для соблюдения национальных интересов меру, а другие - как непозволительное пренебрежение нормами международного гуманитарного права и политическую игру человеческими жизнями. Этот пример позволит нам сравнить освещение острой ситуации гуманитарного характера в двух изданиях разных взглядов.

Наконец, тема иммиграции приобретает наибольший, даже исключительный вес в массмедиа и в общественном сознании в моменты обострения политических и законодательных дискуссий - например, при обсуждении важных законодательных инициатив в этой области (таких как закон «Босси-Фини» 2002 г. и «Пакет по обеспечению мер безопасности 2008 г.») (Villa, 2008: 354). В 2018 г. таким законодательным документом в области иммиграции, вызвавшим горячее обсуждение, стал так называемый «Декрет о безопасности», предложенный Маттео Сальвини и утвержденный Сенатом 27 ноября того же года. Этот документ нацелен на общее усиление публичной безопасности и содержит меры по урегулированию ряда проблем, среди которых иммиграция и организованная преступность.

\section{Методология исследования}

Эмпирическую базу исследования темы миграции в СМИ Италии составили 186 публикаций в онлайн-версиях Corriere della Sera (76) и La Repubblica (110), опубликованные в течение одной недели после каждого из четырех важных для миграционной ситуации Италии событий, привлекших повышенное внимание общественности и СМИ (за исключением выборов 4 марта 2018 г., когда исследовались тексты, опубликованные на протяжении недели до выборов). В результате были выделены основные элементы создания образа миграции и мигрантов.

Для контент-анализа использовался кодификатор, включавший ряд ключевых параметров, которые рассматривались 
исследователями миграционной темы в средствах массовой информации.

Во-первых, мы фиксировали подтемы:

а) внутриполитические дискуссии;

б) внешняя политика;

в) юридические нормы,

г) гуманитарные бедствия;

д) безопасность и преступность;

е) нелегальная иммиграция;

ё) интеграция мигрантов.

Далее было выделено общее отношение к мигрантам и миграции:

а) положительное;

б) отрицательное;

в) нейтральное (какая-либо оценка отсутствует);

г) сбалансированное (в равной мере представлены разные оценки).

Следующим критерием анализа был создаваемый образ мигрантов или миграции:

а) миграция как проблема;

б) мигранты - «такие же люди» (акцент на том, что они обладают теми же правами, что и коренные жители, и являются равноценными членами общества);

в) жертвы;

г) преступники;

д) нелегальные мигранты.

Выделялись категории героев и комментаторов информационных сообщений:

а) национальные политики;

б) региональные политики;

в) иностранные политики;

г) представители некоммерческих организаций;

е) обычные люди;

ё) мигранты;

ж) религиозные организации (церковь);

3) прочие.

Анализировалась также лексика, которую использовали журналисты по отношению к мигрантам и миграции.

Отметим, что рамки исследования были ограничены: рассмотрено лишь четыре недельных периода в 2018 г., определенных четырьмя информационными поводами. Для формирования более полной картины обсуждения миграционной повестки и выявления других точек обострения дискуссии потребовалось бы исследование, охватывающее более длительный временной отрезок, а также большее количество изданий.

Выяснилось, что La Repubblica публикует больше материалов о миграции, чем Corriere della Sera, что говорит о разной степени важности данной темы для изданий (см. табл. 1).

Можно сделать вывод и том, что между ними сохраняется выявленное исследователями ранее (см., напр.: Villa, 2008) различие в подходе к миграционной теме: если La Repubblica ориентируется на отстаивание прав мигрантов и на взаимодействие с организациями гражданского общества, то Corriere della Sera выдерживает более нейтральную позицию и уделяет больше внимания политическому аспекту проблемы. Кроме того, Corriere della Sera чаще остается в рамках освещения фактов происшествия, не всегда заостряя внимание на проблеме миграции как таковой.

И La Repubblica, и Corriere della Sera ведут себя достаточно корректно с этической точки зрения: мы не нашли материалов, настроенных предвзято по отношению к мигрантам или приписывающих отрицательные черты всем мигрантам (см. табл. 2). Источником негативизации темы в таком случае нам представляется ее постоянное обсуждение в контексте проблем, даже если резких негативных суждений по отношению непосредственно к мигрантам практически нет.

Излишне обобщающие негативные суждения из уст журналистов встречаются нечасто, однако подобного рода высказывания позволяют себе политические деятели, такие как Маттео Сальвини и Джорджиа Мелони, что находит отражение в публикациях обеих газет. Ассоциация «Карта ди Рома», как мы уже отмечали ранее, в своих рекомендациях говорит о необходимости внимательно фильтровать такие 

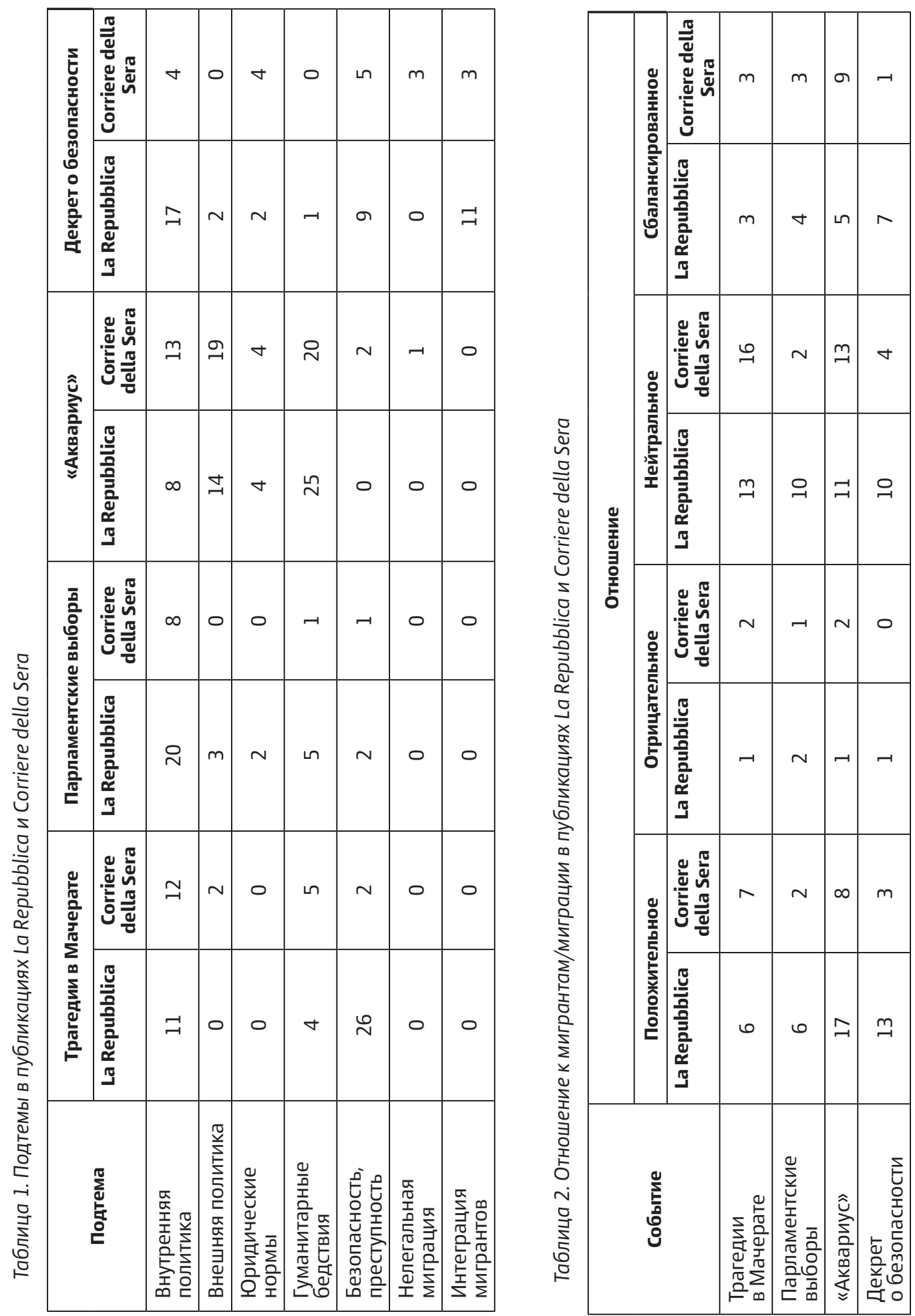
высказывания, в определенных случаях не допуская их попадания в СМИ, даже если они принадлежат известным и влиятельным личностям. Это ставит нас перед вопросом о необходимости баланса между тщательным отбором публичных высказываний с целью предотвратить появление и рост дискриминационных настроений и передачей полной политической картины, включая взгляды различных политических деятелей.

Весьма сильна тенденция к виктимизации мигрантов, более выраженная в La Repubblica. Мигранты представляются в виде «беспомощных жертв», и такой образ способен вызвать сострадание. Однако, с другой стороны, мигранты при такой подаче лишены какой бы то ни было самостоятельности, собственной инициативы, мотивации и власти над своей жизнью.

Этот эффект усиливается за счет крайне малочисленных голосов мигрантов в СМИ. Представляется явным противоречием, что, будучи основными действующими лицами миграционных процессов, мигранты практически исключены из дискуссии. И основной категорией акторов, выражающих интересы мигрантов в средствах массовой информации, остаются неправительственные организации.

В обоих изданиях наблюдалось невнимание к причинам отъезда мигрантов из родной страны, их пути в Италию, к личным историям. Таким образом, мигранты изображаются как жертвы, но не совсем понятно, жертвы чего именно. Более отчетливое понимание этих обстоятельств дало бы аудитории возможность сформировать более полное представление о миграционной проблеме и о мигрантах. Впрочем, это может быть связано также с временными и тематическими ограничениями нашего исследования.

Тема миграции, несомненно, чрезвычайно высоко политизированна, тем более в год выборов: внутриполитические дискуссии составляют большую часть публикаций, посвященных миграции, а национальные политические деятели являются наиболее часто высказывающейся категорией комментаторов. В рамках внутриполитической подтемы миграция рассматривается в первую очередь как проблема, требующая управления,в сущности, как объект политической деятельности. В совокупности с минимальной индивидуализацией темы это приводит к ее дегуманизации: мигранты предстают в виде безликой «массы», за которой не так легко увидеть людей.

\section{Выводы}

Очевидно, что итальянское журналистское сообщество со временем осознало проблему освещения миграционных явлений и необходимость его отслеживания и контролирования этическими органами. О высокой степени важности, которую придают данной проблеме органы саморегуляции журналистов, ясно говорит факт создания специального документа (Римской хартии и приложений к ней) и связанной с ним организации. Ассоциация «Карта ди Рома» в своей деятельности занимает позицию защиты образа и прав мигрантов. Она не только осуществляет медиамониторинг и показывает различные этические аспекты освещения миграционного феномена, но и предоставляет журналистам практические инструменты для более ответственной работы над столь чувствительной для итальянского общества темой.

Несмотря на то, что виктимизирующий взгляд на мигрантов в Италии может пробудить сочувствие и желание помогать слабым, нам представляется, что в нынешних условиях более полезной стратегией было бы озвучивать в средствах массовой информации голоса мигрантов, позволив им тем самым стать равноценными участниками дискуссии о феномене, в котором они являются главными действующими лицами. 


\section{Примечания}

1 Legge N. 69/1963 Ordinamento della Professione di Giornalista, titolo I, art. 2. Режим доступа: http://www.odg.it/legge-n-69-1963/24261 (дата обращения: 03.02.2019).

2 Материалы сайта Союза журналистов Италии. Режим доступа: http://www.odg.it/ ordinamento (дата обращения: 03.02.2019).

3 La Carta dei Doveri del Giornalista (1993). Режим доступа: https://www.fnsi.it/uploa d/9b/9bf3lc7ff062936a96d3c8bdlf8f2ff3/244248f7f921ldb2c6faf72229ddd0e4.pdf (дата обращения: 05.02.2019).

4 Linee Guida per l'Applicazione della Carta di Roma. Strumenti di lavoro per un'informazione corretta sui temi dell'immigrazione e dell'asilo. Associazione Carta di Roma, 2018. С. 7. Режим доступа: https://www.cartadiroma.org/wp-content/ uploads/2018/10/CartadiRoma_WEB_-1.pdf (дата обращения: 05.02.2019).

${ }^{5}$ La Carta di Roma - Protocollo deontologico concernente richiedenti asilo, rifugiati, vittime della tratta e migranti. Режим доступа: https://www.cartadiroma.org/cosa-ela-carta-di-roma/codice-deontologico/ (дата обращения: 06.02.2019).

${ }^{6}$ La Carta di Roma - Protocollo deontologico concernente richiedenti asilo, rifugiati, vittime della tratta e migranti. Glossario. Режим доступа: https://www.cartadiroma. org/cosa-e-la-carta-di-roma/glossario/ (дата обращения: 06.02.2019).

${ }^{7}$ La Carta di Roma - Protocollo deontologico concernente richiedenti asilo, rifugiati, vittime della tratta e migranti.

8 Testo Unico dei Doveri del Giornalista (2016). Режим доступа: http://www.odg.it/testounico-dei-doveri-del-giornalista (дата обращения: 10.01.2019).

9 Материалы сайта Ассоциации «Карта ди Рома». Режим доступа: https://www. cartadiroma.org/chi-siamo/ (дата обращения: 10.02.2019).

10 Linee Guida per l'Applicazione della Carta di Roma. Strumenti di lavoro per un'informazione corretta sui temi dell'immigrazione e dell'asilo. Associazione Carta di Roma. 2018. Р. 27. Режим доступа: https://www.cartadiroma.org/wp-content/ uploads/2018/10/CartadiRoma_WEB_-1.pdf (дата обращения: 11.02.2019).

11 Там же. С. 28.

12 Там же. С. 30.

13 Там же. С. 38.

14 "IlmioraidpervendicarePamela".Trainiconfessatutto.Manonsipente.IlCorrieredellaSera. 04.02.2018. Режим доступа: https://www.corriere.it/cronache/18_febbraio_05/mioraid-vendicare-pamela-85d46088-09fl-1le8-a34a-fc54918998f4.shtml (дата обращения: 05.02.2018).

15 Данные о результатах голосования, доступные на интернет-портале Министерства внутренних дел Италии. Режим доступа: https://elezionistorico.interno.gov.it (дата обращения: 01.03.2019).

${ }^{16}$ Desperate journeys. Refugees and migrants arriving in Europe and at Europe's borders (January-December 2018). UNHCR, January 2019. Р. 8. Режим доступа: https://data2. unhcr.org/en/documents/download/67712 (дата обращения: 02.03.2019).

17 Notizie di chiusura. VI Rapporto Carta di Roma, 2018. Р. 1. Режим доступа: https://www. cartadiroma.org/wp-content/uploads/2018/12/Notizie-di-chiusura.pdf (дата обращения: 05.03.2019). 


\section{Библиография}

Гоффе Н. Италия в зеркале миграционных проблем // Мировая экономика и международные отношения. 2017. Т. 61. № 9. C. 77-88. DOI:10.20542/0131-2227-2017-61-9-77-88

Зонова Т.В. Миграционный аспект глобализации: казус Италии // Научный диалог. 2015. № 1 (37). С. 130-138.

Казаринова Д., де Лука Г. Миграция в итальянском политическом дискурсе: опыт эмпирического анализа // Мировая экономика и международные отношения. 2020. Т. 64. № 2. С. 100-109. Режим доступа: https://doi.org/10.20542/0131-2227-2020-64-2-100-109

Урина Н.В. Италия в информационной картине зарубежных медиа и общеевропейские проблемы в итальянских СМИ (2010-2016 гг.) // МедиаАльманах. 2017. № 3. С. 96-106.

Marini R., Gerli M. (2017) Le forme di un tema. L'immigrazione nell'arena dei quality papers italiani. Comunicazione politica, Quadrimestrale dell'Associazione Italiana di Comunicazione Politica 3: 481-506.

Villa A. (2008) Immigrazione, mass media e ricerca sociale. Problemi dell'informazione, Rivista quadrimestrale. № 3, pp. 348-368. DOI: 10.1445/28116

Wirz D. S. et al. (2018) The Effects of Right-Wing Populist Communication on Emotions and Cognitions toward Immigrants. The International Journal of Press/Politics 23 (4): 496-516. DOI: $10.1177 / 1940161218788956$ 